\title{
A THEORETICAL VIEW ABOUT AGILE MANAGEMENT IN BANK SECTOR
}

\author{
Valentin Partenie MUNTEANU', Paul DRAGOS ${ }^{1}$ \\ ${ }^{1}$ Department of Management, Faculty of Economics and Administrative Affairs, \\ West University, Timisoara, Romania \\ valentin.munteanu@e-uvt.ro \\ paul.dragos90@e-uvt.ro
}

\begin{abstract}
The adoption of Agile methodologies is one of the biggest topics in large organisations and many IT departments nowadays. Banks must introduce new flexible approaches to keep up with the changes in the market, especially regarding the new digital technologies. Large enterprises in all information system programs have implemented Agile approaches because of the widespread benefits. Unlike traditional development model, agile guidelines encourage businesses to follow a straightforward and data-oriented procedure and continually test and learn, rather than producing a final product before testing. This research aims to explore the benefits of Agile approaches in the banking industry and the problems with implementing such methods in product development processes. This study also leads to speedy marketing by offering a minimum viable product (MVP) that satisfies consumers' needs and can be easily adapted. Although various studies explored the implementation of agile principles in multiple contexts, this research is based primarily on the banking software industry. The banking sector must transform itself, to become more digital. However, digital processes are not as simple as in other sectors because banks operate on regulated markets, making it even more challenging to adopt Agile methods. In conjunction with the Agile approaches, this study also illustrates the current management practices. This research is mostly theoretical and qualitative, attempting to complete an existing gap by thoroughly reviewing the existing literature on Agile methodologies for software development and reviewing the standards for banks' software development life cycles. Managing the regulatory climate in which banks work is an essential challenge in optimizing agility. This paper's findings contribute to the field by offering an insight into how Agile approaches can be implemented on the banking setting by analysing the existing literature, with a focus on financial software development.
\end{abstract}

Keywords: Agile Methodology; Agile Banking; Agile development; Iterative approach; Testing approach

\section{JEL Classification: $\mathrm{O} 3$}

\section{Introduction}

The activities of financial services companies are becoming increasingly critical of information technology (IT). Banks are now spending up to $15 \%$ of non-interest expenditure on IT, the bulk of the IT spending in the US economy being made up of financial institutions. Nowadays, banks are more vulnerable to the challenges on the environmental and social level (Carnevale et al., 2012). They have a broader 
role in society and need an Agile framework, probably even more than any other institution. Traditional software development like Waterfall cannot cope with the rapid changes nowadays, and a high rate of systems development (SD) failures are attributed to the conventional methods. Also, the banking sector is a particular sector for using large, monolithic, legacy systems. The fast progress in software development could be more difficult for them to achieve.

The financial services sector seems to be a very complicated business environment that deals with a great deal of knowledge. Even minor gaps in the flow of information have much-reaching effects (Sternkopf, 2018). Consequently, it appears challenging to measure the expenses, challenges, and intensity of a digitalisation project. For this cause, multiple banks are eager to make a move into critically necessary digital transformation.

Major financial entities have traditionally focused on software innovation approaches influenced by the Waterfall method. But even the slightest error in banking and finance systems can lead to the loss of thousands or even millions, particularly when account waves and transfers have to be coordinated with incredible accuracy (Hajrizi and Bytyci, 2015). The system can't fail, or vulnerability to danger is unreasonable. Proper research provisions have prompted many banking and finance companies to remain with the construction of Waterfalls, where the paperwork is incredibly comprehensive, by auditory as well as other regulatory requirements. Therefore, Agile and conventional approaches remain intertwined in the banking sector.

Boehm and Turner (2003) recommended that professionals should go to Agile according to the venture. Organisations are likely to adopt Agile principles if their projects need constant change. If the venture is reasonably stable, standardised methods should be used. Flipping among Agile and formal methods cannot be that fast. If companies want to move between a strictly structured approach and a fully Agile approach, systems engineering companies may be hindered by other powers, which are harder to change.

\section{Literature Review}

The adaptability in the service sector is highly relevant because of the product's intangible nature and the need to create trust amongst stakeholders (Perez et al., 2013). The stakeholder engagement activities must be visible; the project information should be visual to support transparency. Engaging the stakeholders in the agile project is the first step to ensure that the team builds precisely what the customer expects and that the delivered product is of high quality and meets or exceeds expectations (Canty, 2015). The PMI (2013) suggests a number of mechanisms for the stakeholder management of a project, illustrated in Figure 1. 


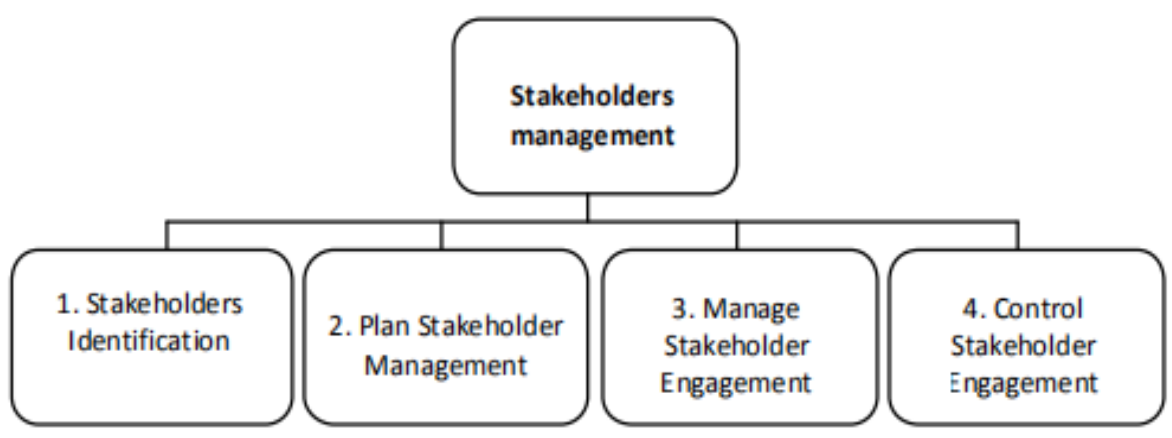

Figure 1: Stakeholders management processes

Source: PMI (2013)

The key stakeholders in the banking industry are: the customers, the investors, the bank clerks, the risk managers, the audit, the IT staff (Murmann, 2018).

In many areas of life, customers have grown used to digital processes over the years and now expect it in all sectors. According to Murrmann (2018), today, with regard to current practise, the customers' standards go far beyond the common practises, such as user-friendliness and accessibility of information, and the availability of information in the 24/7 manner. These subjects like openness of processes, differences between products, and a more established partnership with suppliers and customers are getting increasingly important.

The customer's needs, desires, hopes, and concerns often align with the employee's interests. The employee cares about both the speed and how quickly and how accessible is the data to his customers. By putting together knowledge through systems, he aims to save time and avoid mistakes (Murrmann, 2018).

The organisations test the worthiness of investments in emerging technologies on a case-by-by-case basis, all the way down to the micro stage. The managers and investors aren't expected to be impressed by features, but instead should be persuaded by the facts. They want in particular to see how the digitalization initiative impacts the company's profitability. Questions about the expected productivity improvement, the projected project time and necessary staff are compulsory (Murrmann, 2018).

The modern stakeholders (managers, employees, customers, business partners, local governments, shareholders) work with the organisation (in this case, the bank) to enhance corporate profitability. However, they are not just a way to make money. According to Halal (2001), if the theory that the wealth creation arises directly from integrating stakeholders into a productive whole, a "collaborative enterprise," the companies can claim then legitimate status as dedicated corporate citizens, serving both the economic and social functions of society. Bruyn (1977) even concluded that stakeholders' resources are more significant than shareholders' financial investments by roughly a factor of ten. According to Flavian et al. (2005), maintaining the confidence of stakeholders is vital to the banking sector.

Crosman (2016) found that the Agile development benefits are well-known, not only in one big, long-run "waterfall," but as a way to create applications for small chunks and short spurts: Agile projects are fast-moving, adaptable projects, 
involving working parties, input from end users (continuous tests) and faster outcomes and errors in the process (agility).

Singla (2016) states that the justification for Agile methodology's success in designing financial services, especially in bank applications, is its effective handling of changes in specifications and timelines. The Agile system is agile and versatile. These agile traits become important especially in a climate when the rules of the game can change from one day to another. If regulatory bodies make adjustments to the rules, there will always be possibilities of a sudden shift in specifications and standards. In an Agile environment, it can be easier for the development teams to understand the new criteria (in the sense of the current specifications) and make adjustments to the test situations accordingly.

Agile methodologies don't mean the same thing for every stakeholder, and the concept of Agile differs from one industry to another (Decker, 2004). Often, it is not sufficiently clear which Agile characteristics are likely to trigger a positive stakeholder response. There is a need for a specific model to understand how the stakeholders' project management is performed in an Agile context.

There are some criticisms regarding Agile, especially regarding the boundary conditions. Boehm and Turner (2003) criticised the excuse that agility leads to cowboy-style hacking and limited architectural pre-planning. Fruhling (2006) highlighted the over-reliance on developers' capabilities. It is considered that the tight coordination needed for agility might break down in large teams, that Agile is inappropriate for safety-critical systems, that it risks over-responding to change, rely too much on customer involvement and commitment, and that re-factoring efforts can escalate (DeMarco and Boehm, 2002).

There is not enough research regarding the stakeholders' response in implementing an Agile methodology and the banking industry context. Given that empirical research into agile modelling is not sufficient (Capiluppi, 2007) and the above criticisms of Agile, a research model linking Agile's upsides and downsides with the stakeholders' satisfaction is needed. Like any other method or tool, the Agile methodologies must be finely tuned to a given institution's specifics, in this paper, the institutions being the banks.

\section{Agile Approach for Software Development in Banking}

The consumer experience, in the banking environment, can be controlled by the agile supplier. The organisation makes judgments based first on what is most appropriate for the customer and then on what is most suitable for the financial system. Banking has a robust competitive choice regarding consumer data, opportunities, and personal levels. By applying strong analytics and an agile approach, an appropriate treatment is developed quickly and resiliently. An Agile system helps to engage customers with more innovative results. The continuous development and improvement of customer-oriented products can encourage banks to demonstrate their customer knowledge (Keita, 2020). Figure 2 represents the procedure of a true Agile approach. 


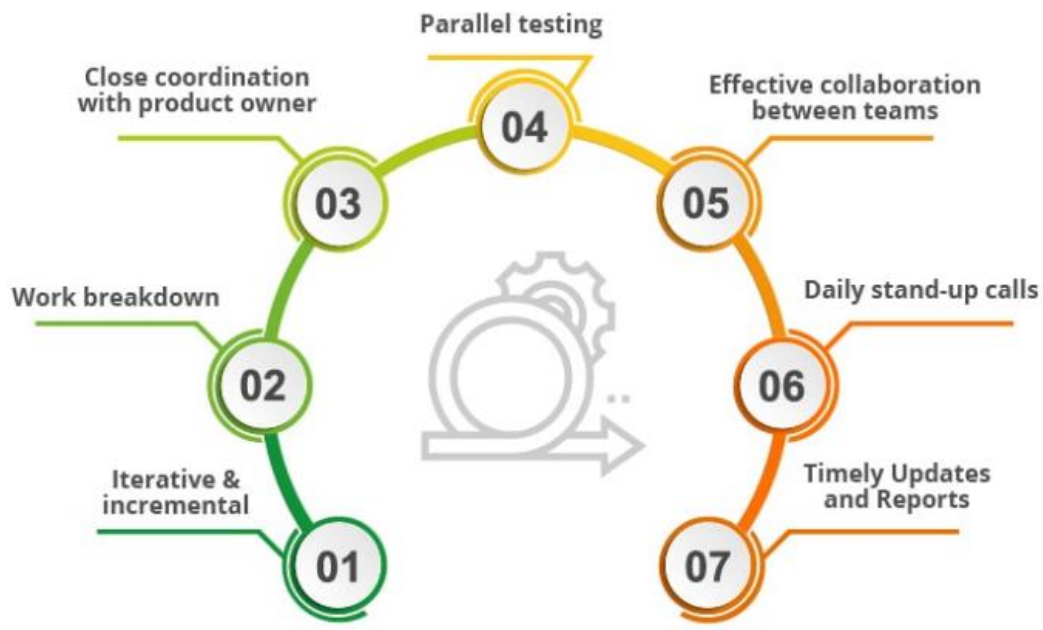

Figure 2: Agile Methodology Framework

Source: (TestingXperts, 2021)

According to Chintala (2015), there are some critical areas which must be carefully considered when it comes to software development and they are: continuous Testing, Omni-channel testing (e.g. assure consistent customer experience across channels), customer experience, analytics validations (validate structured and unstructured data, test the accuracy of data etc.), Cyber Security QA.

Financial services firms must take three paths to conquer the agility obstacles and they are presented below.

Assessment and Preparation of the Company: they need to recognise the internal impediments to agility and build a path to resolve them. They need to describe their vision.

Preparations for deployment: the goal of agile change is to develop consumer value rapidly. Companies can then build teams based on distinct customer experiences. These teams operate better when managers exhibit 'servant leadership'-that is, they often eliminate obstacles that can slow down the work of digital product teams instead of working in conventional control and command mode.

Community and technology network support: financial services firms must use advanced information and design architectures such as microservices and application programming interfaces (APIs), which benefit from the latest technologies in infrastructure and cloud-based systems to support new products' agile development. Product developers must also follow an automated system culture - wherever possible manual labour is transformed into automated work.

When it refers to the implications of adopting Agile toward conventional workplace and administration models, the most important benefit provided by Agile is that it reveals corporate dysfunctions (Javanmard and Alian, 2015). If any significant adjustments are made in an Agile approach, the group will not suspend the working mechanism; instead, it will decide how and where to effectively manage 
the adjustments that arise across the project. In development, the evaluation process throughout an Agile approach often arises quicker (Bhattacharjee, 2012). Agile software projects thrive at a set longitudinal rhythm or pulse. The constant flow of new, tested features each time offers feedback that keeps the project and the system on track. The agile software development procedure can be seen in Figure 3.

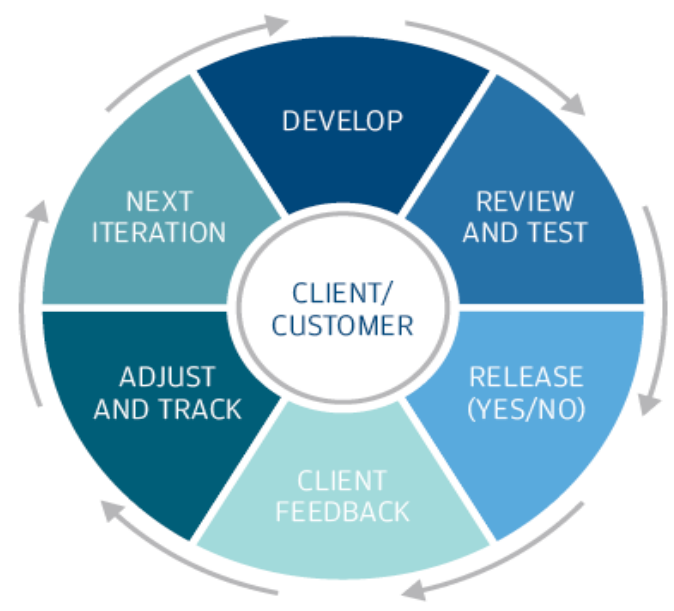

Figure 3: Agile Development

Source: (Rodrigues, 2018)

The fundamental positive characteristics of the Agile approach are presented in Table 1.

Table 1: Agile Modelling (AM) characteristics

\begin{tabular}{|l|l|}
\hline AM characteristics & Description \\
\hline Iterative Development & $\begin{array}{l}\text { Quick delivery of small working (and tested) software } \\
\text { releases at regular intervals or cycles. }\end{array}$ \\
\hline Continuous Integration & $\begin{array}{l}\text { After every task (in the ideal case), the last version of } \\
\text { the code is added to the production base code. }\end{array}$ \\
\hline Collective Ownership & $\begin{array}{l}\text { Any developer has the right to add or maintain the } \\
\text { code anywhere in the system at any time. }\end{array}$ \\
\hline Test-Driven Design & $\begin{array}{l}\text { Developers write tests before they do code. This can } \\
\text { motivate developers to plan better before starting to } \\
\text { code. }\end{array}$ \\
\hline Feedback & $\begin{array}{l}\text { Frequent feedback loops with customers allow } \\
\text { developers to ascertain the functionality's accuracy. }\end{array}$ \\
\hline
\end{tabular}

Source: (Ferreira and Cohen, 2008)

However, there are some things to consider when adopting an Agile methodology. The first negative factor is the limited architectural pre-planning. Even though Agile permits constant changes, solid initial requirements are highly essential to have clear initial visions. The developers should consider this step of pre-planning as one of the most critical steps in the project. Agile works better on solid ground.

The second negative factor is the over-reliance on the capabilities of developers. In an Agile environment, the developers have higher ownership over the project. 
However, the lack of central leadership might be an issue, especially when facing a critical problem.

The third negative factor is the risk of over-responding to change. Trying to satisfy the stakeholders by answering every one of their requirements is detrimental to the business. There are legitimate requests and non-legitimate requests for change, and an Agile team must know how to differentiate between them.

The fourth negative factor is relying too much on customer involvement and commitment. The customer might be the king, but even the king sometimes is not sure of what he desires from a product. Often, the sellers (the bank's employees) can guide the customers effectively to the best solution for their case.

Also, suppose the customers are not as involved or committed as expected. In that case, the banks might not get enough feedback from them to make the necessary iterations, characteristics to an Agile process. In this case, they better get creative in attracting more customers or getting ahead without too much customer involvement while maintaining the Agile methodologies for other aspects of the development process.

The nine factors of Agile (5 positives and 4 negatives) are linked to the stakeholder's satisfaction, which has two divisions: process satisfaction and outcome satisfaction. In the development process, the stakeholders will be negatively influenced by any perceived problem (Kim et al., 2006). To avoid this, the development process should go smoothly, with an excellent way to tackle the eventual problems which might arise. According to (McKeen 2004), the more satisfied are the stakeholders with the development process, the more likely the system will reflect their requirements and meet their expectations. Consequently, the more likely they will accept the system and take ownership. In other words, the more they are satisfied with the development process, the more they will be satisfied with the development outcome. Figure 4 compiled all the factors and their impact on stakeholders' satisfaction.

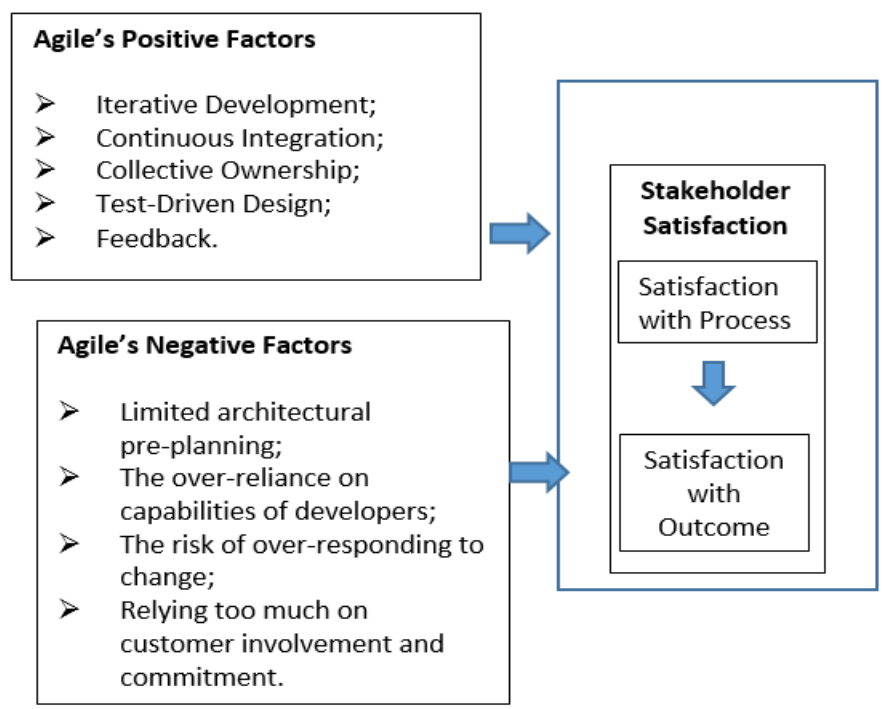

Figure 4: Conceptual Model

Source: Adapted from Ferreira and Cohen (2008) 


\section{Conclusion}

Agile requires connecting all the stakeholders and, as a concept, Agile is still a work in progress, just like the applications developed under Agile concepts. As such, it might be the time to reassess the progress and see what worked, what did not work, what could be done better, and how Agile could improve. Several businesses continue to work in their old-fashioned way, but this way of doing business is not sustainable in the long run. A company cannot expect the same thing over and above to yield exponentially, unbelievably impossible performance. Under the Agile methodology, the job has only started after a sprint has been completed. The Agile team needs to have a sprint summary meeting at the end of each sprint where the team addresses successes and weaknesses and how to refine the strategy continuously. This is the ticket for a team that expands, goes quicker, and creates better financial software.

\section{References:}

1.Bhattacharjee, V. (2012), "Comparison Between Agile and Traditional Software Development Methodologies", EzineArticles, available at: https://ezinearticles.com/?Comparison-Between-Agile-and-Traditional-SoftwareDevelopment-Methodologies\&id=7162906 (accessed on March 2021)

2.Boehm, B. and Turner, R. (2003), Balancing Agility and Discipline: A Guide for the Perplexed, Addison-Wesley Professional.

3.Bruyn, S. (1977) The Social Economy (New York: Wiley).

4.Canty, D. (2015). Agile for project managers. CRC Press.

5.Carnevale, C., Mazzuca, M., \& Venturini, S. (2012). Corporate social reporting in European banks: the effects on firm market value, Corporate Social Responsibility and Environmental Management, 19, 159-177.

6.Capiluppi, A., Fernandez-Ramil, J., Higman, J., Sharp, H.C., and Smith, N. 2007. An empirical study of the evolution of an agile-developed software system. Proceedings of the 29th International Conference on Software Engineering (Minneapolis, MN, USA, 2007).

7.Chintala, S. and Mohan, N. (2015), "The intricacies of software testing", available at: https://bankingfrontiers.com/the-intricacies-of-software-testing/ (accessed on March 2021).

8.Crosman, P. (2016), "Agile Development Is Reshaping Tech at Banks Like Chase and BBVA", American Banker, available at: https://www.americanbanker.com/news/agile-development-is-reshaping-tech-atbanks-like-chase-and-bbva (accessed on March 2021).

9.Decker, O.S. (2004). Corporate social responsibility and structural change in financial services. Managerial Auditing Journal, 19, 712-728.

10. DeMarco, T. and Boehm, B. (2002) 'The agile methods fray', Computer, 35(6), pp. 90-92. doi: 10.1109/MC.2002.1009175.

11. Ferreira, C., \& Cohen, J. (2008, October). Agile systems development and stakeholder satisfaction: a South African empirical study. In Proceedings of the 2008 annual research conference of the South African Institute of Computer Scientists and Information Technologists on IT research in developing countries: riding the wave of technology (pp. 48-55). 
12. Flavian, C., Guinaliu, M., Torres, E. (2005). The influence of corporate image on consumer trust :a comparative analysis in traditional versus internet banking, Internet Research, 15, 447-470.

13. Fruhling, A. and De Vreede, G-J. (2006). Field experiences with eXtreme programming: developing an emergency response system. J. Manage. Inform. Syst. 22,4 (2006), 39-68.

14. Hajrizi, E. and Bytyci, F. (2015), "Agile Software Development Process at Financial Institution in Kosovo", IFAC-PapersOnLine, Vol. 48 No. 24, pp. 153156.

15. Halal, W. E. (2001). The collaborative enterprise: A stakeholder model uniting profitability and responsibility. Journal of corporate citizenship, (2), 27-42.

16. Javanmard, M. and Alian, M. (2015), "Comparison between Agile and Traditional software development methodologies", Vol. 36 No. 3, p. 9.

17. Keita, B. (2020). Why Agile Is Extremely Essential for Banking | Invensis Learning. [online] Invensis Learning Blog. Available at: https://www.invensislearning.com/blog/agile-is-essential-for-banking/ (accessed on March 2021).

18. Kim, H. and Pan, S.L. (2006). Towards a process model of information systems implementation : the case of customer relationship management (CRM). The DATA BASE for Advances in Information Systems. 37, 1 (Winter 2006), 5976. (accessed on March 2021)

19. Murmann, S. (2018), "The Most Important Stakeholders in the Digital Transformation of Finance", available at: https://www.knowis.com/blog/the-mostimportant-stakeholders-in-the-digital-transformation-of-finance (accessed on March 2021)

20. Perez, A., Garcia de los Salmones, M.M., \& Rodriguez del Bosque, I. (2013). The effect of corporate association on consumer behavior. European Journal of Marketing, 47, 218-238.

21. PMI (2013), "A guide to the project management body of knowledge", 5th Edition, Newton Square: Pennsylvania.

22. Rodrigues, K., 2018. Building an Agile Business. Available at: https://www.jpmorgan.com/commercial-banking/insights/building-agile-business (accessed on March 2021).

23. Singla, G. (2016), "Agile and testing: What banks need to know", Finextra Research, 27 August, available at: https://www.finextra.com/blogposting/13021/agile-and-testing-what-banks-needto-know (accessed on March 2021).

24. Sternkopf, C. (2018), Software Testing Help, "The Implementation of a Banking Software for the Lending Sector in Practice", available at https://www.knowis.com/blog/implementation-of-a-banking-software-for-thelending-sector-in-practice (accessed on March 2021).

25. TestingXperts. 2021. Agile Methodology - An Effective Guide for Businesses. Available at: https://www.testingxperts.com/blog/agile-methodology (accessed on March 2021). 